\title{
Triangelns mellanrum - bisexuellt begär som kritik och teori
}

\author{
Av Malena Gustavson, Tema genus, Linköpings universitet[i]
}

Bisexualitet i betydelsen dubbelt begär brukar tolkas som en tudelning, en splittrad sexualitet som står och väger mellan två attraherande poler. Splittringen förstärks också med föreställningar om bisexuella som omogna, obestämda och kanske opålitliga gentemot dem som kommit ut som homosexuella. Sociologen Amber Ault pekar till exempel på hur bisexuella kvinnor i vissa lesbiska kretsar pekas ut som avvikare och hur bisexuella blir marginaliserade inom en redan marginaliserad grupp (Ault 1995). Marginaliseringen eller utanförskapet beror på att bisexuella antas kunna passera som heterosexuella. Jag återkommer till bisexualitetens gränspasserande och frågan om det heterosexuella privilegiet.

\section{Uttalad kategori och tystnader}

Många vill definiera och kontrollera sexualitet. Förutom vetenskapliga modeller, till exempel Kinseyskalan, som delar in sexuellt beteende på en glidande skala från noll till sex finns de vardagliga definitionerna, erfarenheterna och uttrycken. Dessa kan variera beroende på vem som talar. Frågan är vem som talar i följande definition ur Nationalencyklopedin:

bisexualitet (av lat. bi- 'två' och sexualitet), erotiskt intresse för båda könen, med förmåga till såväl hetero- som homosexuella relationer. Dessa relationer kan alternera eller existera parallellt. Inom sexologin betraktas vanligen bisexualitet antingen som en variant av heterosexualitet eller homosexualitet eller som en särskild, tredje form av sexuell identitet och orientering.

Samhället intar ofta en mer positiv hållning till bisexualitet än till homosexualitet. /.../ (Nationalencyklopedin 1990:594)

Nationalencyklopedins mål är att upplysa om vetenskapliga fakta och kunskap.

Upplysningen om bisexualitet i stycket är tillsynes objektiv och neutral och verkar ha formulerats utifrån en idé om korrekta fakta. Bisexualitet definieras här som förmågan att ha sexuella relationer med såväl kvinnor som män. Detta ska då, enligt texten praktiseras antingen som seriell monogami eller som flera parallella relationer. Att det även i homooch heterosexuella relationer utövas seriell monogami eller relationer med flera partner samtidigt förblir oproblematiserat i Nationalencyklopedin. Andra former, som trekanter och gruppsex nämns inte i NE.

Formuleringen "som en särskild, tredje form av sexuell identitet och orientering" säger egentligen ingenting om vad denna tredje form skulle innebära, vilket snarare säger något om de tomrum mellan dikotomin homo-hetero. I Nationalencyklopedin hävdas också att "samhället intar en mer positiv hållning till bisexualitet än till homosexualitet". Ett sådant påstående utgår från en heterosexuell norm, där samhället framstår som neutralt, utan laddning eller värdering. Påståendet utgår från en normativ och universalistisk maktposition som gör anspråk på att bedöma och diskriminera sexuell annorlundahet. Homo- och bisexuella kan ju inte rimligtvis räknas in i ett sådant samhälle. Hur göra en radikal biteoretisk kritik när det heterosexuella samhället intar som det verkar en "mer positiv hållning"? 


\section{Bisexuell kunskap}

Bisexualitet som kritisk och teoretisk diskussion förhåller sig på olika sätt till feministisk teori och queerteori. Feministiska kunskapsmål syftar till att blottlägga de maktförhållanden som reproducerar genushierarkier, medan queerteorins huvudsakliga område är att dekonstruera heterosexuell normalitet, alltså att heterosexualitet inte är självklart eller naturligt utan en social och kulturell konstruktion. Gemensamt för feministisk teori, queeroch biteori är kritiken av maktrelationer som organiserar genus och sexualitet.

Biteorin, framför allt i England och USA, försöker framför allt lyfta fram representationer av bisexualitet och hur bisexualitet producerar ny kunskap i mellanrummet mellan homohetero (jfr Hemmings m fl. 1997). För bisexualitet är tystat och osynligjort även i queerteorin och i feminismen, vilket innebär att den bisexuella erfarenheten och den bisexuella kunskapen inte har räknats. Biteorin menar att det tomrum som verkar finnas mellan dikotomin homo-hetero, t ex. i citatet från Nationalencyklopedin "en särskild tredje form" är istället en kunskapsarena som osynliggörs och negligeras inom genusforskning, sexualkunskap och kritisk sexualteori.

Ett bisexuellt kunskapsmål som jag vill peka på i min forskning är att rikta kritik mot hegemonisk tvåsamhet. Med tvåsamhet avser jag homo-, bi- och heterosexuella parrelationer. Tvåsamheten har få alternativa utmaningar i västerländsk kultur, eller rättare sagt, dessa alternativ kommer sällan till uttryck som ett legitimt eller socialt accepterat sätt att organisera relationer. Tvåsamheten grundar sig i en föreställning om en heterosexuell reproduktion, en föreställning om arbetsdelning och grundläggande skillnad mellan könen. Tillspetsat kan man uttrycka den traditionella tvåsamheten som ett sätt för fäder att kontrollera sin avkomma, sin hustrus och sin egen sexualitet, vilket också upprätthåller en androcentrisk ordning.

\section{Tvåsamheten och trekanter}

Tvåsamheten kan också ses som en performance eller en ritual som gör relationer meningsfulla i vår samtid. Om vi definierar vårt samhälle som androcentriskt, ett välde av kunskap, vanor och föreställningar som historiskt grundar sig på att gifta fäder har haft tolkningsföreträde till att definiera och utöva makt, kan vi anta att dessa män vid makten haft anledning att vara bekymrade. För hur ska monogamin kunna försäkras, hur ska ett androcentriskt styre kunna försvaras och hur blir heterosexualitet normalt?

Dessa queera frågor knyter an till den foucaultska traditionen om begär som motstånd mot normativa maktrelationer. Allt som hotar att destabilisera tvåsamheten blir farligt och lockande i klassisk tabuanda när det närmar sig gränsen för det otillåtna, och klassas som promiskuöst eller naturvidrigt. Detta kan länkas till sekelskiftets skräck för besudelse, som blev ett sätt att skilja natur från kultur (jfr Frykman \& Löfgren 1979).

Jämför med triangeldramat, som är ett av de vanligaste teman i litteraturen enligt. Litteraturforskaren Eve Kosofsky Sedgwick. Hon menar att begäret struktureras i en trianguläritet, som både bevarar heterosexuell tvåsamhet och sätter den på spel (Sedgwick 1985:21). Banden mellan de män, i konkurrens om kvinnan, uttrycker ett homosexuellt begär som måste avstyras och kvinnan måste därmed upprättas som ett föremål för åtrå. Eftersom heterosexualiteten i den romantiska litteraturen skall bestå måste männen rivalisera om att äga den åtrådda, vilket garanteras genom parbildningen.

Om man istället laddar triangeldramat med ett bisexuell begär, menar biteoretikern Marjorie Garber, förskjuts också de inbördes relationerna och meningssammanhangen (Garber 2000: 428). Symbolerna i triangeldramat får en annan innebörd, eftersom en erotisk laddning riktas mellan alla de involverade parterna. Detta ger möjlighet att kunna dekonstruera föreställningen om det heterosexuella privilegiet. 


\section{Heterosexuellt privilegium}

Att passera som heterosexuell i en heteronormativ kontext är inte oproblematiskt. Heterosexuellt privilegium måste därför definieras (jfr Gustavson 1998). Om det betyder att slippa bli utpekad som avvikande betyder det att accepteras i ett heteronormativt samhälle, som utesluter bi- och homosexuellt begär, vilket knappast kan godtas ur en bisexuell position. Det heteronormativa samhällets välvilja blir då en tom, meningslös gest.

Om heterosexuellt privilegium betyder att reproducera ett system som i grund och botten är kvinnoförtryckande är det inte längre ett privilegium. Det heterosexuella privilegiet är alltså relationellt till kontexten. För att undgå ett cirkelresonemang finns det anledning att istället se bisexuellt gränsöverskridande ur ett annat perspektiv.

Om bisexualitet innebär att appropriera, det vill säga överta de homo- och heterosexuella praktikerna och diskurserna och göra dem till sina egna, blir bisexualitet en strategi som öppnar upp för alternativ och förhandling snarare än en kategoriskt gränsdragning. Gränserna blir luddiga och oanvändbara. Till exempel får parrelationer då en annan innebörd på grund av närvaron av begärets ambivalens och tvetydighet. Att på så sätt överskrida tvåsamhetens fundamentalism utgör bisexualitet ett motstånd där Nationalencyklopedins samhälle inte längre kan inta en positiv hållning.

\section{(C) Malena Gustavson}

\section{Bibliografi}

Ault, Amber. 1995: "Hegemonic Discourse in an Oppositional Community: Lesbian Feminists and Bisexuality" I: Rethinking Marxism. A Journal of Economics, Culture and Society. Vol.8/1995 s. 107-122.

Frykman, Jonas \& Löfgren, Orvar (red). 1979: Den kultiverade mäniskan. Liber läromedel. Lund.

Garber, Marjorie. 2000: Bisexuality and the eroticism of everyday life. Routledge. New York.

Gustavson, Malena . 1998: "Både varken eller - det dubbla begäret konceptualiserat" I: S.CR.A.M - Swedish Critical Art Magasine 2/1998. Genarp.

Gustavson, Malena. 2001: "...till tygellöst leverne: en bisexuell kritik av tvåsamhetens hegemoni" Lambda Nordica 1-2 (2001), Stockholm.

Hemmings, Clare. 1997: "Bisexual Theoretical Perspectives: Emergent and Contingent Relationships" I: The Bisexual Imaginary. Representation, Identity and Desire. Red. Bi Academic Invention. Cassell, London.

Nationalencyklopedin 1990, vol 2. "bisexualitet" s. 594. Bra Böcker. Höganäs.

Sedgwick, Eve Kosofsky. 1985: Between Men : English Litterature and Male Homosocial Desire. Columbia University Press, New York.

Storr, Merl. 1999: Bisexuality. A Critical Reader. Red. Merl Storr. Routledge. London, New York.

[i] Pappret utgår från min artikel "...till tygellöst leverne: en bisexuell kritik av tvåsamhetens hegemoni" Lambda Nordica 1-2 (2001). Även nätpublicerad på http://home.swipnet.se/pernin/mg/texts/lambda01.htm 